\title{
Unjuk kerja kulkas termoelektrik dengan rangkaian seri dan paralel pada beban air $1500 \mathrm{ml}$
}

Hendra Ananta, Yesung Allo Padang, Mirmanto*

Teknik Mesin, Fakultas Teknik, Universitas Mataram, Jln. Majapahit No.62 Mataram, Nusa Tenggara Barat, Kode Pos : 83125, Telp. (0370) 636087; 636126; ext 128 Fax (0370) 636087

*Email : mmirmanto@gmail.com

\section{ARTICLE INFO}

Article History:

Received February 2017

Accepted October 2017

Available online 30 December 2017

\section{Keywords:}

Refrigerator

Thermoelectric module

Series and parallel

COP

In cooperation with SNMI XI 2017

Special Edition

\begin{abstract}
Along with the increase of human mobility, the portable refrigerator becomes very important because it can be used to store goods or drinks to be durable or cooler. Therefore, a refrigerator using thermoelectric is an option. Thermoelectric fridge besides easy to carry anywhere is also easy maintenance, durable, more compact, lightweight, no heavy rotating components, no use of freon and small power. Refrigerator research with thermoelectric has been done with series and parallel electric circuits to know the effect of the circuit difference to the performance of refrigerators. This study uses a mini fridge with an overall dimension of $40.8 \mathrm{~cm} \times 32.6$ $\mathrm{cm} \times 53.8 \mathrm{~cm}$ and with 2 thermoelectric modules TEC112706 model. The electrical power used for each circuit is about $12 \mathrm{~W}$. The data retrieval in the test uses $D A Q$ MX $9714 \mathrm{NI}$ data logger which is connected to the PC using LabView program. The results show that the test research with a water load of $1500 \mathrm{ml}$ results in the temperature of the refrigerator room of about $22.54^{\circ} \mathrm{C}$ for the series and $23.10^{\circ} \mathrm{C}$ for the parallel. While the value of COP obtained with the series circuit is 0.45 and with the parallel circuit is 0.4 . There is no effect of the form of the circuit on the performance of the refrigerator.
\end{abstract}

\section{PENDAHULUAN}

Kulkas atau lemari es, adalah sebuah alat pendingin yang dapat menjaga kesegaran makanan yang berada di dalamnya, Pramana (2015). Namun seiring dengan perkembangan teknologi, kita menyadari bahwa terdapat hal yang merugikan apabila kulkas menggunakan refrigeran yang mengandung CFC. Disamping itu sistem kompresi biasanya lebih berat sebab terdapat komponen yang dikosntruksi untuk mampu menahan tekanan tinggi. Oleh sebab itu ukuranya biasanya relatif besar. Kelemahan lain dari kulkas yang menggunakan refrigeran adalah kebocoran sebab menggunakan fluida. Namun demikian, pendingin sistem kompresi menjadi lebih baik jika diterapkan untuk kapasitas besar sebab COP-nya tinggi atau lebih dari 1. Untuk mengatasi hal tersebut perlu dihadirkan kulkas tanpa freon, misalnya kulkas menggunakan termoelektrik.

Keuntungan kulkas ini tidak banyak menggunakan komponen yang berputar (tidak 
bising), tidak ada masalah kebocoran, bentuk kompak sehingga dimensi totalnya dapat lebih kecil, tahan lama, perawatan mudah dan daya yang digunakan rendah. Namun demikian terdapat kelemahan yaitu kurang bagus untuk kapasitas tinggi sebab COP-nya masih di bawah 1. Penelitian tentang kulkas termoelektrik pernah dilakukan, tetapi COP-nya juga masih di bawah 1. Irwin dkk, (2013) meneliti tentang kotak pendingin berukuran $16 \mathrm{~cm} \times 8 \mathrm{~cm} \times 9 \mathrm{~cm}$ dan kapasitas minuman kaleng sebesar $330 \mathrm{ml}$ dengan termoelektrik bersumber dari arus DC kendaraan dalam rangkaian seri dan paralel. Dalam penelititannya daya yang dibutuhkan sebesar 60 Watt yang diambil dari baterai kendaraan. Hasil yang didapat adalah temperatur pendinginan fluida antara $6-8^{\circ} \mathrm{C}$ selama kurang lebih 2 (dua) jam. Nilai unjuk kerja COP peralatan yang digunakan sebesar 0,856. Mereka menyimpulkan bahwa rangkaian parallel lebih baik dibandingkan rangkaian seri. Kemudian Ramdhan (2016) Meneliti tentang sistem pendingin pada kulkas termoelektrik dengan variasi pembebanan. Ramdhan (2016) meneliti kulkas termoelektrik dengan menggunakan 3 modul termoelektrik tipe TEC-12706 yang disusun secara paralel. Ukuran kulkas mini yang digunakan berukuran 40,8 $\mathrm{cm} \times 32,6 \mathrm{~cm} \times 53,8$ $\mathrm{cm}$ dengan memvariasikan beban pendinginan. Beban pendinginan yang digunakan adalah air minum dengan $0 \mathrm{ml}$ (tanpa air) variasi $600 \mathrm{ml}$, $1500 \mathrm{ml}, 3000 \mathrm{ml}$ dan $4500 \mathrm{ml}$ selama 210 menit. Daya yang digunakan sekitar $51,27 \mathrm{~W}$ dan hasil yang didapat adalah temperatur ruang kulkas tanpa beban sebesar $14,07^{\circ} \mathrm{C}$, dengan beban $600 \mathrm{ml}$ sebesar $16,08^{\circ} \mathrm{C}$, beban $1500 \mathrm{ml}$ sebesar $17,07^{\circ} \mathrm{C}$, dengan beban $3000 \mathrm{ml}$ sebesar $18,47^{\circ} \mathrm{C}$ dan dengan beban $4500 \mathrm{ml}$ sebesar $20,83^{\circ} \mathrm{C}$. Ketika beban pendingin meningkat dan daya tetap, maka COP juga meningkat.

Suhu $6-8^{\circ} \mathrm{C}$ atau $14,07^{\circ} \mathrm{C}$ sudah dapat digunakan untuk menyegarkan minuman. Namun demikian, daya yang digunakan masih besar. Oleh sebab itu, pada penelitian ini akan dikaji unjuk kerja kulkas termoelektrik dengan daya sekitar 12 W. Rangkaian susunan listrik termoelektrik (seri dan paralel) juga akan diteliti yang mana nanti pengaruh rangkaian listrik ini dapat dikonfrontir dengan hasil penelitian Irwin dkk., (2013). Hasil penelitian ini nantinya dapat diharapkan menjadi salah satu acuan dalam perencanaan kulkas termoelektrik yang lebih baik. Tujuan dari penelitian ini yaitu untuk mengetahui unjuk kerja mesin pendingin

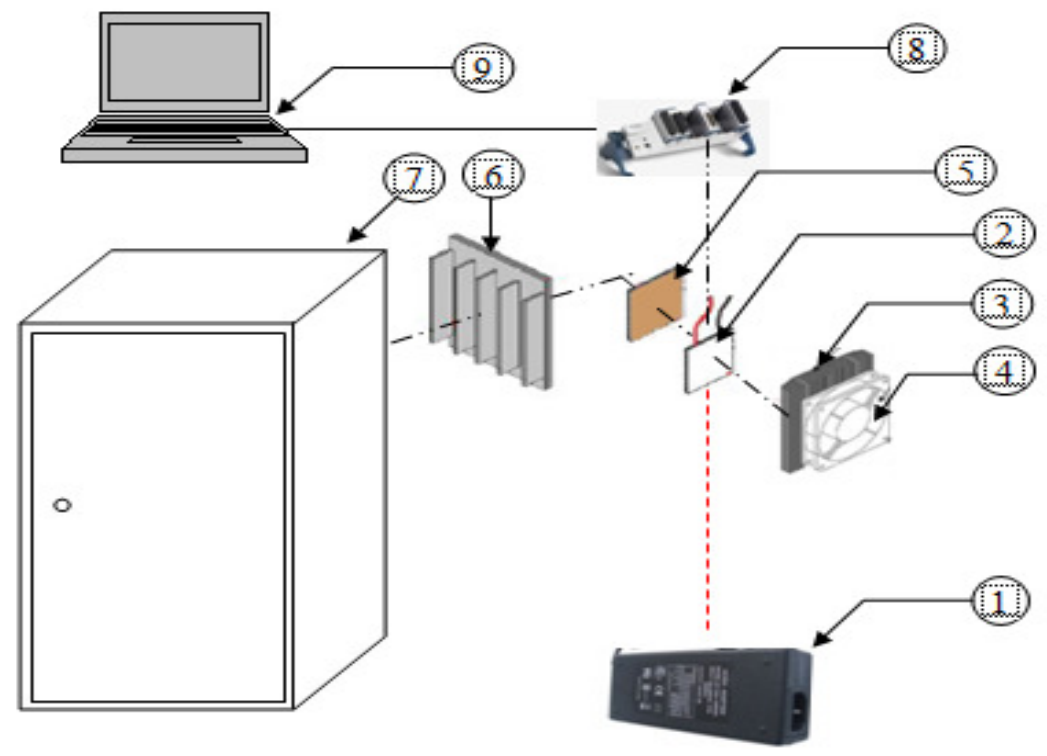

1. Adaptor, 2. Termoelektrik, 3. Heat sink luar, 4. Kipas, 5. Plat tembaga, 6. Heat sink dalam, 7. Kotak kulkas, 8. DAX NI 9714, 9. Komputer/Laptop

Gambar 1. Skema instalasi alat penelitian, Ramdhan (2016) 
termoelektrik untuk susunan seri dan paralel dan untuk mengetahui nilai COP dari masing-masing rangkaian.

\section{METODE PENELITIAN}

Penelitian didefinisikan sebagai penyelidikan yang sistematis terorganisir pada fakta atau data, kritis, dan ilmiah terhadap permasalahan yang dilakukan untuk mendapatkan penyelesaian yang objektif. sisi panas dan dingin, beban pendinginan dari udara, air dan konduksi serta data COP.

Skema alat penelitian ditunjukan pada gambar 1 yang terdiri dari kulkas termoelektrik yang ukuranya $40,8 \mathrm{~cm} \times 32,6 \mathrm{~cm} \times 53,8 \mathrm{~cm}$, dua buah modul Peltier, heatsink luar, kipas, tembaga, heatsink dalam, data logger DAQ NI 9417, komputer dan adaptor 12 V-5 A. Semua suhu diukur menggunakan termokopel tipe $\mathrm{K}$ yang telah dikalibrasi dengan ketidak pastian

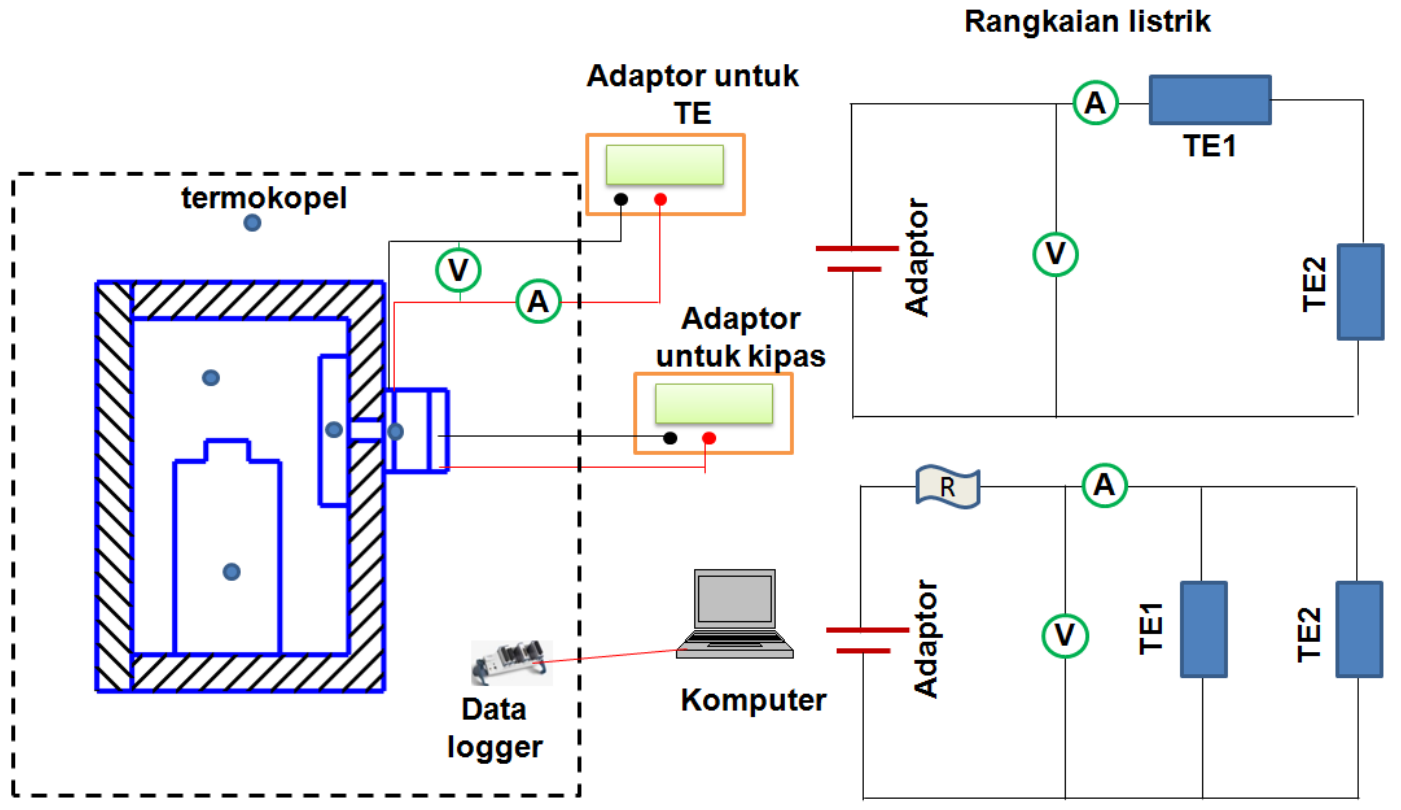

Gambar 2. Rangkain termoelektrik seri dan paralel yang digunakan pada penelitian, TE adalah termoelektrik

Sedangkan metode penelitian didefinisikan sebagai cara-cara yang digunakan dalam merancang penelitian, pengumpulan data dan analisis data serta cara-cara pengambilan kesimpulan. Pada penelitian ini, metode yang digunakan adalah metode ekperimental, yaitu melakukan pengujian langsung terhadap alat uji agar memperoleh data-data yang diinginkan untuk menjawab/menyelesaikan permasalahan. Modul termoelektriknya disusun secara seri dan paralel, lihat gambar 2.

Variabel bebas dalam penelitian ini adalah rangkaian termoelektrik seri dan paralel pada sedangkan variabel tetapnya adalah daya listrik dan beban air minum $1500 \mathrm{ml}$. Variabel terikat yang akan diperoleh adalah suhu ruangan, suhu air minum, suhu lingkungan, suhu termoelektrik (error) $\pm 0,5^{\circ} \mathrm{C}$. Tegangan yang digunakan 11,94 $\mathrm{V}-1,03 \mathrm{~A}$ (daya 12,3 W) untuk seri dan 6,04 V$1,99 \mathrm{~A}$ (daya 12,02 W) untuk yang paralel. Tegangan dan arus diukur dengan menggunakan multimeter.

\section{HASIL DAN PEMBAHASAN}

Sebelum menyajikan hasil hitungan beban pendinginan dan COP, maka pencatatan terhadap temperatur terutama temperatur ruangan penting untuk diberikan. Gambar 3 menunjukan tren suhu kondisi transien terhadap waktu atau time dependence. Pada gambar 3 nampak bahwa suhu ruangan dan suhu air menurun dengan bertambahnya waktu. Menurunya suhu ruangan dan suhu air disebabkan panas di dalam ruangan kulkas 
diserap oleh heat sink dalam yang diteruskan ke pada sisi dingin termoelektrik. Karena ruangan tertutup dan dinding kulkas menggunakan material isolator panas seperti styrofoam maka makin lama suhu dalam ruangan makin turun. Tetapi dari gambar 3, terlihat bahwa turunya suhu ruangan lebih cepat dibandingkan dengan suhu air. Hal ini disebabkan air berada di dalam botol, sehingga pengambilan panas dari air sedikit terhambat oleh botol plastik yang bersifat hampir sama dengan isolator. Suhu ruangan (TR) terendah yang diperoleh dengan rangkaian seri adalah $22,54^{\circ} \mathrm{C}$, sedangkan dengan rangkaian paralel adalah $23,1^{\circ} \mathrm{C}$, lihat gambar 4 . Perbedaan ini tidak siknifikan sebab selisihnya hanya $\left(0,56^{\circ} \mathrm{C}\right)$ atau $2,4 \%$ dari $23,1^{\circ} \mathrm{C}$ yang artinya masih berada di dalam jangkauan ketidak pastian (error) yang besarnya $\pm 0,7^{\circ} \mathrm{C}$.

Gambar 3 tersebut sangat berguna untuk menghitung atau menganalisis beban pendinginan. Beban pendinginan pada penelitian ini tentu terdiri dari beban udara dalam kulkas, beban air minum 1500 ml dan beban konduksi. Beban pnedinginan dari udara dan air dapat diprediksi dengan menggunakan beberapa persamaan. Persamaan energi yaitu yang digunakan untuk menghitung energi panas dari udara atau air. Persamaan ini ditunjukan dengan persamaan (1), Holman (1995):

$$
E_{u}(i)=m_{u}(i) c_{p_{u}}(i)\left[T_{u}(i)-T_{u}(i-1)\right]
$$

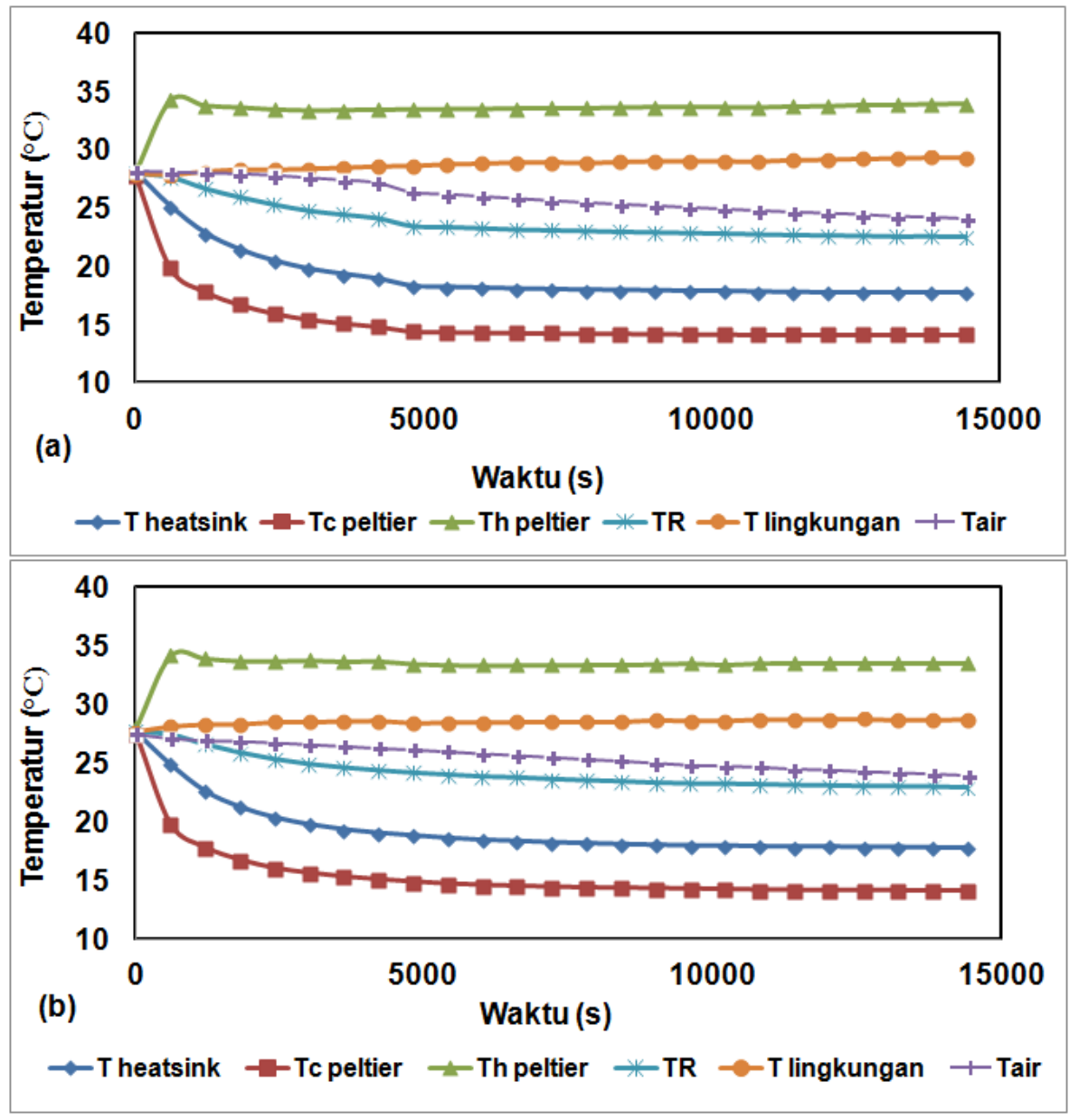

Gambar 3. Tren suhu dari dalam ruangan kulkas dan dari termoelektrik untuk (a) rangkaian seri, (b) rangkaian paralel, pada beban air minum $1500 \mathrm{ml}$ 


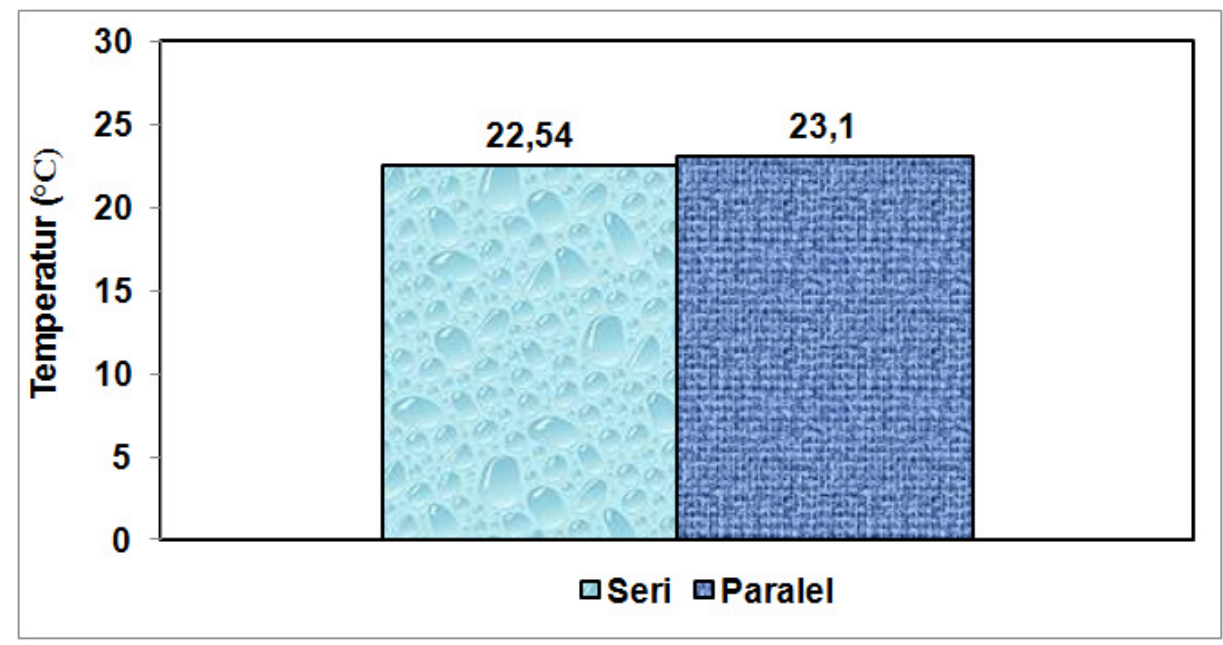

Gambar 4. Pengaruh jenis rangkaian terhadap temperatur minimum ruang kulkas yang dicapai pada beban pendinginan air minum $1500 \mathrm{ml}$

Tabel 1. Hasil perhitungan pada rangkaian paralel dengan beban air $1500 \mathrm{ml}$

\begin{tabular}{ccccccc}
\hline Percobaan & $\mathrm{Q}_{\mathrm{k}}$ & $\mathrm{Q}_{\mathrm{u}}$ & $\mathrm{Q}_{\mathrm{a}}$ & $\mathrm{Q}_{\mathrm{C}}$ & $\mathrm{P}_{\mathrm{in}}$ & $\mathrm{COP}$ \\
\hline Rangkaian seri & 3,84 & 0,01 & 1,63 & 5,48 & 12,30 & 0,45 \\
Rangkaian paralel & 3,66 & 0,01 & 1,48 & 5,15 & 12,02 & 0,43 \\
\hline
\end{tabular}

$E_{a}(i)=m_{a}(i) c_{p_{a}}(i)\left[T_{a}(i)-T_{a}(i-1)\right]$

Dengan $E_{u}$ dan $E_{a}$ adalah energi yang harus dipindahkan dari udara dan dari air minum (J), $c_{p}$ panas jenis $(\mathrm{J} / \mathrm{kg} \mathrm{K})$ dan $T$ adalah suhu udara atau air $\left({ }^{\circ} \mathrm{C}\right)$. Persamaan (1) untuk udara di dalam ruangan kulkas dan persamaan (2) untuk air minum di dalam ruangan kulkas di dalam botol. Persamaan di atas juga digunakan oleh Ramdhan (2016) dan Musa (2017).

Sementara itu untuk mencari atau menghitung laju aliran panas dari udara atau air minum dapat diprediksi dengan, Holman (1995):

$Q_{u}=\frac{\sum_{1}^{n} E_{u}(i)}{t}$
$Q_{a}=\frac{\sum_{1}^{n} E_{a}(i)}{t}$

Dimana $Q$ adalah laju aliran kalor (W), sub-scribt $u$ dan a menyatakan untuk udara dan air minum, sedangkan $t$ adalah total waktu observasi (s). Dengan menggunakan persamaan (1) sampai dengan 4, diperoleh laju aliran kalor seperti ditunjukan pada tabel 1 , dengan simbol $Q_{u}$ dan $Q_{a}$. Persamaan (3) dan (4) adalah modifikasi dari persamaan kesetimbangan energi yang dapat dilihat di Holman (1995). 


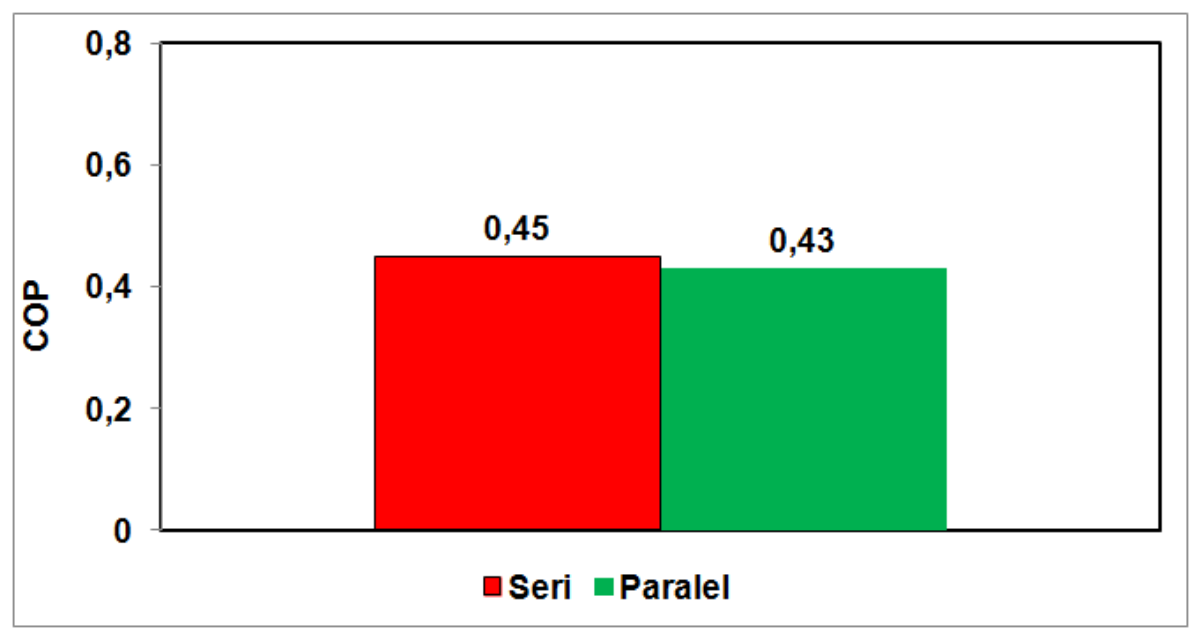

Gambar 5. Pengaruh variasi rangkaian TE terhadap COP

Beban pendinginan lainya adalah beban dari konduksi melalui dinding kulkas. Karena terdapat perbedaan suhu antara ruangan kulkas dan lingkunganya maka terjadi perpindahan panas yang masuk dari lingkungan ke dalam ruangan kulkas. Energi konduksi, $E_{k}$, dapat diprediksi dengan persamaan, Holman (1995):

$$
\begin{aligned}
& E_{k}(i)=\frac{T_{w o}(i)-T_{w i}(i)}{R}(t(i)-t(i-1)) \\
& R=\frac{x_{1}}{k_{1} A_{1}}+\frac{x_{2}}{k_{2} A_{2}}+\frac{x_{3}}{k_{3} A_{3}}
\end{aligned}
$$

Dimana $T_{\text {wo }}$ dan $T_{w i}$ adalah suhu dinding kulkas luar dan dalam dan dinding kulkas yang digunakan terdiri dari 3 material yang berbeda, lihat tabel 2. $R$ adalah tahanan termal $\left({ }^{\circ} \mathrm{C} / \mathrm{W}\right), x_{1}$, $x_{2}$ dan $x_{3}$ merupakan tebal material 1, material 2 dan material 3 yang menyusun dinding kulkas. $A_{1}, \quad A_{2}, \quad A_{3}$ menyatakan luasan permukaan konduksi tegak lurus arah aliran kalor konduksi yaitu tegak lurus dinding kulkas. Namun demikian sebagai beban pendinginan yang diperlukan adalah laju aliran kalornya, oleh sebab itu, jumlah dari hasil persamaan (5) harus dibagi dengan total waktu observasi, Holman (1995):

$$
Q_{k}=\frac{\sum_{1}^{n} E_{k}(i)}{t}
$$

Hitungan menggunakan persamaan (7) disajikan pada tabel 1 . Total beban pendinginan sama dengan jumah beban pendinginan yaitu, Rifat and Ma (2003):

$$
Q_{C}=Q_{u}+Q_{a}+Q_{k}
$$

Hitungan $Q_{C}$ juga disajikan pada tabel 1. Tujuan terakhir dari percobaan ini adalah menentukan COP yang dapat diestimasi sebagai, Rifat and Ma (2003):

$$
C O P=Q_{C} / P_{i n}=Q_{C} / V I
$$

Dengan $P_{\text {in }}$ adalah daya masuk yang besarnya sama dengan $V I$ yaitu tegangan dikalikan dengan arus dan variabel ini diukur dengan menggunakan multimeter. Hasil hitungan COP dapat dilihat pada gambar 5. Dari gambar 5, dapat dilihat bahwa perbedaan COP untuk rangkaian seri dan rangkaian paralel berbeda sangat kecil yaitu sekitar 0,02 saja atau 4,65\% dari 0,43. Andaikan data dianggap tingkat kepercayaanya adalah $95 \%$ atau error $5 \%$, maka perbedaan $4,65 \%$ masih lebih rendah dari $5 \%$. Oleh sebab itu, dapat dikatakan bahwa pengaruh rangkaian tidak siknifikan terhadap COP. Namun demikian, COP hasil percobaan masih juga di bawah 1. Hal ini juga diemukan oleh Ramdhan (2016), Musa (2017), Riffat and Ma (2003). Untuk itulah perlu penelitian lebih lanjut untuk meningkatkan COP. 


\section{KESIMPULAN}

Dari hasil penelitian dan pembahasan tersebut dapat disimpulkan beberapa hal sebagai berikut :

1. Suhu ruangan menurun dengan bertambahnya waktu observasi.

2. Temperatur ruangan kulkas minimal pada penelitian ini dengan beban $1500 \mathrm{ml}$ air minum $22,54^{\circ} \mathrm{C}$ untuk rangkaian seri dan $23,10^{\circ} \mathrm{C}$ untuk rangkaian paralel dengan percobaan dilakukan selama 14400 detik.

3. COP yang dihasilkan 0,45 untuk rangkaian seri dan 0,43 untuk rangkaian paralel.

4. Pengaruh rangkain seri dan paralel boleh dikatakan tidak siknifikan sebab hasil percobaan dari ke dua rangkaian hampir sama pada beban air minum yang sama dan day yang hampir sama.

\section{UCAPAN TERIMAKASIH}

Pada kesempatan ini penulis menyampaikan banyak terimakasih yang sebesarbesarnya kepada semua pihak yang tidak dapat disebutkan satu persatu, yang telah membantu baik berupa moril maupun materiil. Penulis juga mengucapkan terimakasih kepada Jurusan Teknik Mesin, Universitas Mataram untuk fasilitas yang digunakan dalam melakukan penelitian.

\section{DAFTAR PUSTAKA}

Holman J.P., 1995, Perpindahan kalor, Edisi ke VI. Erlangga Jakarta.

Irwin B., Rury A., 2013, Kaji eksperimental kotak pendingin minuman kaleng dengan termoelektrik bersumber dari arus dc kendaraan dalam rangkaian seri dan paralel, Seminar Nasional Tahunan Teknik XII, Bandar Lampung.

Musa Z., 2017, Pengaruh daya terhadap unjuk kerja kulkas termoelektrik, Skripsi Jurusan Teknik Mesin, Universitas Mataram.

Pramana L., 2015, Freezer dengan daya 1/6 pk dan panjang pipa kapiler $150 \mathrm{~cm}$, Departemen Teknik Mesin Fakultas Sains dan Teknologi Universitas Sanata Dharma, Yogyakarta.

Ramdhan G., 2016, Sistem pendingin pada kulkas termoelektrik dengan variasi pembebanan. Skripsi Teknik Mesin Universitas Mataram.

Riffat S.B., Ma X., 2003, Review: Thermoelectrics: a review of present and potential applications, Applied Thermal Engineering, 23, 913-935. 